\title{
A importância da afetividade na Creche
}

\author{
The importance of affectivity in daycare
}

Marinéa Figueira Rodrigues ${ }^{\dagger *}$, Rosângela Batista Freire

Como citar esse artigo. Rodrigues, MF; Freire, RB. A importância da afetividade na Creche. Revista Mosaico. 2017 Jan./Jun.; 08 (1): 11-16.

\begin{abstract}
Resumo
Este trabalho tem por objetivo mostrar a importância da creche para o desenvolvimento infantil onde o brincar, como proposta pedagógica, e a afetividade devem fazer parte do currículo dessas instituições, tendo como princípio o cuidar e o educar como conteúdo indissociável nessa tarefa. A creche deve ser um lugar prazeroso onde a criança brinca para aprender e aprende para brincar, para se socializar, se desenvolver e crescer em conjunto e em interação com seus pares. Nesse contexto, o afeto é um elemento de extrema importância durante todo o processo de ensino-aprendizagem, devendo permear todo o planejamento da prática pedagógica, pois é também nessa etapa, que o indivíduo forma hábitos, valores, atitudes construindo as bases de sua personalidade. Partindo dessa premissa buscaram-se livros de autores que versam sobre o assunto assim como documentos que legitimam os direitos da criança a uma educação de qualidade.

Palavras-Chave: Criança; Desenvolvimento Infantil; Educação Infantil
\end{abstract}

\begin{abstract}
This work aims to show the importance of daycare for child development where playing is regarded as a pedagogical approach, and affectivity should be part of the curriculum of these institutions, taking the care as principle and education as inseparable content in this task. The daycare should be a pleasant place where children play to learn and learn to play, to socialize, to develop and grow together in interaction with their peers. In this context, affection is an extremely important element throughout the process of teaching and learning, it should permeate all the planning of teaching practice, because it is also at this time of life that the individual shapes habits, values, attitudes, building the foundation of his/her personality. From this premise, authors that deal with this subject, as well as documents that legitimize the rights of children to quality education, were sought.

Keywords: Child; Child development; Child education.
\end{abstract}

\section{Introdução}

Segundo Eichmann (2014), a creche, atualmente, é vista dentro de um contexto formal de educação, apoiando às necessidades básicas das crianças, mas cumprindo também uma função assistencial, já que os pais ou responsáveis necessitam deixá-las num local seguro durante o seu período laboral. Nesse sentido, a entrada da criança na creche, hoje, não visa apenas resolver as necessidades da família, mas sim, envolver a criança em um processo educativo para o seu desenvolvimento infantil.

$\mathrm{Na}$ área educacional, observa-se que hoje nas creches, cuida-se e educa-se. Procedimentos, esses, indissociáveis para um pleno desenvolvimento da criança. Tais ações acontecem com qualidade, ou não, de acordo com fatores que podem propiciar uma proposta educativa e de cuidado com a organização do ambiente e do tempo, pela proposta de atividades, pelos recursos disponíveis, pela organização do programa e pelo currículo da Educação Infantil. (BUJES; KAERCHER, 2001)

Partindo desses princípios, esse estudo foi realizado tendo como base uma revisão de literatura sobre a importância da creche para o desenvolvimento infantil, levando em consideração o cuidar e educar, aliado aos profissionais envolvidos nessa tarefa. Foram consultados documentos como, as Diretrizes Curriculares Nacionais para Educação Infantil (2010), o Referencial Curricular para a Educação Infantil (1998), a Constituição de 1988, a Lei 9394/96, entre outros que tratam o assunto.

O diálogo com autores como RIZZO (2006), KRAMER (2006), WALLON (1995), dentre outros não menos importantes, e artigos no banco de dados Scielo que permitiu elucidações acerca da problemática em estudo, sendo considerado um ponto de partida no desenvolvimento da pesquisa.

Afiliação dos autores: $\uparrow$ Possui graduação em Pedagogia pela Universidade Santa Úrsula (1981).Pós - Graduada em Problemas do Desempenho Escolar pela Faculdade de Humanidades Pedro II e Mestrado em Ensino de Ciências da Saúde e do Ambiente pelo Centro Universitário Plínio Leite. Atualmente Coordenadora do Curso de Pedagogia,Professora Assistente II da Universidade Severino Sombra -Vassouras/RJ.

\$ Graduada em Pedagogia pela Universidade Severino Sombra. Professora do Instituto Thiago Costa e da Escola Municipal Prefeito Severino Ananias Dias.

* rosangelabsr@yahoo.com.br 


\section{A creche}

Segundo Rizzo (2006, p. 46), a creche existe para exercer, pela família os cuidados básicos de saúde e educação indispensáveis ao bem-estar da criança a partir dos três meses de idade, cuidando de sua segurança física e emocional, durante o horário de afastamento de seus pais.

\section{Pressupostos históricos da creche}

Durante grande parte da história da humanidade, a educação e o cuidado das crianças pequenas ficaram sob o âmbito familiar ou do grupo social ao qual elas pertenciam, não existindo qualquer instituição responsável que compartilhasse da educação das crianças menores de três anos. Assim que a criança era desmamada, ingressava no mundo adulto, ajudando nas atividades cotidianas, que a integravam no meio social. Nas classes mais abastadas, as crianças eram reverenciadas como se fosse um objeto divino, mas a sua transformação em adulto, também, ocorria via imersão no ambiente doméstico.

Bujes (2001) explicita que a educação da criança deveria ser junto aos adultos e outras crianças de sua convivência, com o intuito de levá-la a aprender os conhecimentos básicos e participar das tradições, tão imprescindíveis a sua sobrevivência material e enfrentamento da vida adulta.

Corroborando tais ideias, Ariès (1981, p. 231) argumenta que a família

[...] não podia, portanto nessa época, alimentar um sentimento existencial profundo entre pais e filhos. Isso não significa que os pais não amassem seus filhos. [...] A família era uma realidade moral e social, mais do que sentimental.

Partindo dessa premissa, verifica-se que durante um longo período a sociedade ignorou, rejeitou e menosprezou a infância tornando-a despercebida da antiguidade até os meados do século XIII. O aborto provocado era visto de forma natural, o que causava uma enorme mortalidade infantil, principalmente, com o apoio da alta sociedade, para esconder a vergonha da mãe solteira, pois mulheres e crianças não tinham qualquer valor, sendo considerados seres inferiores. (RIZZO, 2006)

Nesse sentido, Rizzo (2006) aborda que a questão da menos-valia da criança era justificada pelo fato das mães de classes mais abastadas aceitarem o afastamento de seus filhos, que eram entregues às amas de leite, de cujas mãos só voltavam anos mais tarde para serem entregues aos seus preceptores, isso quando não morriam por maus tratos, falta de higiene e comida. Sobre as amas de leite, Morgado (2004) salienta que o objetivo das mesmas, era incrementar sua renda, cuidando de outras crianças que não fosse seus filhos biológicos.

Embora, grande parte da educação da criança pequena esteja alijada ao contexto doméstico, foram criados e construídos muitos arranjos alternativos para prestar cuidado às crianças em situação desfavorável.

Tais arranjos vão desde o uso das redes parentais, nas sociedades primitivas, ou de "mães mercenárias", já na Idade Antiga, até a criação de "rodas" - cilindros ocos de madeira, giratórios, construídos em muros de igrejas ou hospitais de caridade que permitiam que bebês fossem neles deixados sem a identidade de quem os trazia precisasse ser identificada - para recolhimento dos "expostos" ou a deposição de crianças abandonadas em "lares substitutos", já na Idade Média e Moderna. A responsabilidade por esse recolhimento ficava a cargo de entidades religiosas, que procuravam fazer com que os enjeitados fossem conduzidos a um ofício, quando crescessem. (OLIVEIRA, 2010, p. 59)

Baseando-se na citação acima, percebe-se que várias foram as ideias que nortearam as formas precárias de atendimento a menores durante muito tempo: "pobreza, culpa, favor e caridade". (OLIVEIRA, 2010, p. 59)

Segundo Rizzo (2006), o aparecimento da indústria transformou intensamente a estrutura social vigente, o que ocasionou modificações nos costumes da família e no papel desempenhado pela mulher na sociedade, resultando em grandes mudanças com relação à proteção da criança.

Faria (1997, p. 12) argumenta que "o contexto da Revolução Industrial, do Iluminismo e da Constituição dos Estados Laicos nos oferece o registro das primeiras iniciativas de atendimento à infância." Esse atendimento eram realizados em locais denominados "refúgios" ou "asilos" e eram destinados às crianças, filhas de mães solteiras e surgiram na França através dos movimentos de cunhos filantrópicos e assistenciais.

Rizzo (2006) afirma que o francês João Frederico Oberlim, foi o primeiro a apresentar uma opção de escola para crianças de dois a seis anos. A preocupação principal era atender as crianças de uma classe em ascensão - a burguesia, mas não configurou-se na ideia de abrigo, nem de escola em horário integral, sendo a primeira intenção voltada para a Educação Infantil. Não criou raízes, por não ter uma linha filosófica que a solidificasse. Somente, em fins do século XVIII e início do século XIX, que a creche surge na Europa com o propósito de atender crianças de 0 a 3 anos, durante o período de trabalho das famílias. (SANCHES, 2003)

Em 1844, Firmim Marbeau, cria em Paris a primeira creche, cujo significado em português é manjedoura ou presépio, lugar onde os animais recebem comida (criança à semelhança dos animais). "[...] Foi criada a primeira instituição, com a específica finalidade de evitar a desgraça e que se tornara o serviço das gardeuses d'enfants, transformando, então em faiseuses d'anges (aborteiras)". (RIZZO, 2006, p. 33) 
Na Alemanha Friedrich Froebel, um influente e importante educador que se preocupou com a educação dos pequenos na faixa etária de três a seis anos, criando o jardim de infância, com o objetivo de desenvolver nas crianças suas potencialidades, liberdade de expressão e criatividade. (RIZZO, 2006)

De acordo com Oliveira (2010, p. 73), "o século XX começou com vários passos dados em direção à consolidação do estudo científico da criança". A partir desse período médicos, educadores e sanitaristas, fizeram-se presentes na orientação do atendimento prestado às crianças em instituições fora da família. Foram criados programas de atendimento (estimulação precoce nos lares e em creches) para minimizar a mortalidade infantil, já que o número de órfãos havia aumentado, consideravelmente, após a Primeira Guerra Mundial.

\section{A creche no Brasil}

Os primeiros passos da História da Educação Infantil no Brasil têm acompanhado toda a trajetória da história dessa área no mundo, com suas características próprias. $\mathrm{O}$ atendimento de crianças pequenas, longe de suas famílias em instituições como creches ou locais apropriados a essa idade, praticamente não existia em nosso país, até meados de século XIX. Essa situação só sofreu transformações a partir da segunda metade deste século, quando ocorreu a abolição da escravatura, o processo de migração para a zona urbana das grandes cidades, o desenvolvimento cultural e tecnológico e o surgimento do regime republicano como forma de governo. (OLIVEIRA, 2010)

Até a Proclamação da República, as iniciativas de proteção à infância, eram quase nulas, não passando de ações isoladas, quando muito de combate às altas taxas de mortalidade infantil da época. Com a abolição da escravatura, surgem novos problemas, como o que fazer com os filhos dos escravos, que já não assumiriam o lugar de seus pais, o que de certa forma gerou o aumento considerável do abandono de crianças e a busca de soluções para o problema da infância. Criaram-se, então, as creches, asilos e internatos, reconhecidos na época como instituições assemelhadas e destinadas aos menos afortunados.

Corroborando tais ideias, Oliveira et al. (2011, p.24) afirma que "até o início do século XX, o atendimento das crianças em creches não se distinguia do atendimento em asilos e internatos." Era destinado aos filhos de mães solteiras que não tinham condições de criá-los. Essas mulheres carregavam consigo o sentimento de pecado e culpa e o atendimento institucional a seus filhos era tido como uma caridade.

Com a implantação da indústria no país, na segunda metade do século XIX, houve a necessidade de incorporar um grande número de mulheres casadas ou solteiras no trabalho nas fábricas. As mulheres que eram mães se defrontaram com o problema do cuidado a seus filhos, o que gerou muitas soluções solitárias, pois cada uma delas procurava resolver o seu problema, às vezes pagando vizinhas para cuidar deles.

A chegada dos imigrantes europeus ao Brasil, no início do século XX, para trabalhar nas fábricas, modificou esse cenário, pois um novo tratamento passou a ser dado aos filhos dos operários, já que eram muitas as reivindicações e protestos contra as condições de trabalhos nas fábricas, entre elas creches para os seus filhos. Para diminuir a força dos movimentos operários, os donos de indústrias foram concedendo certos benefícios sociais (vilas operárias, clubes esportivos, creches e escolas maternais para os filhos de seus empregados), buscando com isso controlar o comportamento dos operários, dentro e fora da fábrica. Apesar dessas conquistas, muitos foram os conflitos, e as creches criadas não passavam de paliativos, um "mal necessário".

Nas décadas de 30, 40 e 50, as creches existentes fora das indústrias eram de responsabilidade de entidades filantrópicas, e recebiam donativos das famílias mais ricas de cada região e mais tarde ajuda governamental para desenvolver suas atividades.

As creches também eram defendidas por médicos e sanitaristas que se preocupavam com a higiene das condições de vida da população mais pobre e o trabalho junto às crianças nas creches. Segundo Oliveira et al. (2011, p. 24), "era de cunho assistencial-custodial. A preocupação era com alimentação, higiene e segurança física das crianças".

Não se valorizava um trabalho voltado para a educação, para a parte cognitiva e afetiva da criança.

No período de 1930 a 1960, alguns grupos sociais passaram a defender a creche como agência promotora de bem-estar social, preocupando-se em promover medidas de saúde junto à população mais pobre, como forma de prevenir a marginalidade e a criminalidade, sendo compreendida como uma "dádiva aos desafortunados". (OLIVEIRA et al., 2011, p. 26)

Surge nessa conjuntura, à teoria da privação cultural, invocada nos anos 70 e 80 , ao considerar que $\mathrm{o}$ atendimento à criança pequena em creches possibilitaria a superação das precárias condições sociais a que ela estava sujeita, em defesa de uma educação compensatória. Sob esse ponto de vista, Kramer (2006) relata que as crianças oriundas das classes sociais dominadas “são consideradas 'carentes', 'deficientes', 'inferiores' na medida em que não correspondem ao padrão estabelecido. Faltariam a estas crianças, 'privadas culturalmente', determinados atributos ou conteúdos que deveriam ser nelas incutidos". (KRAMER, 2006, p. 24)

Da década de 80 até hoje aumentaram o número de 
creches mantidas por empresas industriais e comerciais e por órgãos públicos para o filho de seus funcionários, inclusive algumas empresas disponibilizam verbas para os seus funcionários pagarem uma creche particular de sua preferência.

A Constituição de 1988 veio repensar e refletir as funções da creche, reconhecendo-a como instituição educativa, "um direito da criança, uma opção da família e um dever do Estado", (OLIVEIRA et al., 2011, p. 29). Mas, a sua operacionalização ainda é muito deficiente nos dias atuais.

\section{Creche: conceito atual}

A concepção de creche, como um espaço educativo, é relativamente recente, afirmando Rizzo (2006) que é um ambiente especialmente criado para estimular o desenvolvimento integral e harmonioso da criança sadia nos seus primeiros três anos de vida e responder pelos cuidados da criança na ausência da família.

\section{Legislação pertinente}

A legislação brasileira busca na sua trajetória garantir atendimento às crianças de 0 a 6 anos começando pela Constituição Federal de 1988 e passa para o Estado essa responsabilidade com a ampliação de creches e pré-escolas. Trazendo nos seus Capítulos II, dos direitos sociais e III da Educação "o direito dos trabalhadores urbanos e rurais - à assistência gratuita aos filhos e dependentes em creches e pré-escolas". (BRASIL, 1988)

O Estatuto da Criança e do Adolescente (1990) prevê no seu Capítulo II Do Direito à Liberdade, ao Respeito e à Dignidade, Art. 15 que: "A criança e $\mathrm{o}$ adolescente têm direito à liberdade, ao respeito e à dignidade como pessoas humanas em processo de desenvolvimento e como sujeitos de direitos civis, humanos e sociais garantidos na Constituição e nas leis". (BRASIL, 1990, p.14)

Com a criação da Lei 9394 de Diretrizes e Bases da Educação Nacional (LDB) a Educação Infantil passou a fazer parte da primeira etapa da Educação Básica, sendo oferecida em creches e entidades equivalentes no seu Artigo 30, inciso I. (BRASIL, 1996)

Alei $n^{\circ} 11.274$ de 2007 altera a redação dos artigos $\mathrm{n}^{\mathrm{o}} 29,30,32$ e 87 da Lei n ${ }^{\circ} 9.394$, de 20 de dezembro de 1996, que estabelece as Diretrizes e Bases da Educação Nacional, dispondo sobre a educação de 9 (nove) anos para o Ensino Fundamental, com matrícula obrigatória a partir dos 6 anos de idade, diminuindo a idade de finalização da Educação Infantil para 5 (cinco) anos.

O Referencial Curricular Nacional da Educação Infantil(1998), foi um marco, pois reforçou a importância da Educação Infantil, enfatizando o desenvolvimento afetivo, cognitivo, social e emocional da criança de 0 a 6 anos. (BRASIL, 1998)

A Educação Infantil, segundo as Diretrizes Curriculares Nacionais para a Educação Infantil (2010), deve ser "oferecida em creches e pré-escolas, às quais se caracterizam comoespaços institucionais não domésticos que constituem estabelecimentos educacionais públicos ou privados que educam e cuidam de crianças de 0 a 5 anos de idade". (BRASIL, 2010, p. 33)

O Plano Nacional de Educação (PNE, 2014), prevê 20 metas para serem cumpridas nos próximos 10 anos. Já na primeira Meta o plano determina:

Universalizar, até 2016, a educação infantil na pré-escola para as crianças de 4 (quatro) a 5 (cinco) anos de idade e ampliar a oferta de educação infantil em creches, de forma a atender, no mínimo, 50\% (cinquenta por cento) das crianças de até 3 (três) anos até o final da vigência deste PNE. (BRASIL, 2014, p. 9)

Esta meta em vigência para ser cumprida, não depende somente do acesso dessas crianças, mas também do ambiente adequado, qualificação profissional, saúde, alimentação, entre outros fatores essenciais a uma educação de qualidade que visam o desenvolvimento integral da criança.

\section{A importância da afetividade do professor na Creche}

Segundo Paniagua e Palacios (2007), o apego é a mais profunda de nossas emoções, sendo a primeira emoção interpessoal e, mais duradoura e permanente ao longo de toda a nossa existência. É considerado um laço emocional importante que estabelecemos com as pessoas que consideramos mais significativas e indispensáveis para nós, pelo simples fato de sua presença nos trazer segurança e nos proporcionar satisfação, o que faz delas, nosso "porto seguro" já que recorremos a elas ao primeiro sinal de medo, fraqueza, fragilidade e nos momentos de aflição.

A primeira e mais importante instituição social que a criança faz parte é a família, com exceção de casos extremos, como adoção, internatos etc., a família é considerada um vínculo no qual podemos obter as primeiras informações do cotidiano vivenciado pela criança. As crianças da creche, em especial as de 0 a 3 anos, se comunicam afetivamente, pois quanto mais forem cuidadas, amadas e interagirem com as pessoas de sua convivência, mais sensíveis se tornarão em seu convívio. (WALLON, 1995) Para este autor, a expressão emocional precede a linguagem verbal, tornando possível fornecer a vida coletiva as suas primeiras impressões.

Partindo dessa premissa, na creche a criança tem oportunidade de se socializar e se desenvolver, 
de brincar e crescer em conjunto e em interação com seus pares. Nesse contexto, o afeto é um elemento de extrema importância durante todo o processo de ensinoaprendizagem, devendo permear todo o planejamento da prática pedagógica, pois é também nessa época, que o indivíduo forma hábitos, valores, atitudes para construção das bases de sua personalidade.

Qualquer ação psicopedagógica planejada para essa faixa etária tem que estar implantada em fortes bases afetivas, pois o desabrochar da inteligência se faz envolvido em profundas emoções, todas frutos da convivência do aluno com o seu educador. (RIZZO, 2006, p. 81)

Para tanto, cabe ao professor não conceber a criança apenas como um somatório de intelecto mais personalidade como partes isoladas em si mesmas, mas sim compreendê-la como um indivíduo integral em formação de sua personalidade, em que qualquer inferência do meio deixará profundas marcas na sua maneira de ver, de pensar e sentir.

O ponto de partida de qualquer trabalho pedagógico deve ser a emoção. Como vimos, a emoção do aprendente apropria-se do que é aprendido e, desta forma, o afeto atua no início do processo de aprendizagem para canalizar a atenção e no final para ajudar a memória no resgate das informações. (CUNHA, 2008, p. 44)

Segundo Cunha (2008), quando o aluno se sente amado o seu desejo de aprender aumenta e quando ele alcança o aprendizado, alcança também a felicidade, elevando assim, sua autoestima, o que torna o desenvolvimento do afeto algo determinante em sua vida.

Nos primeiros anos de vida, a criança necessita muito do adulto, e a relação que ela mantiver com ele será fundamental ao processo, seja de formação de sua personalidade, quanto de sua aprendizagem. "O adulto é o intermediador entre a criança e o objeto de sua ação e conhecimento. $\mathrm{O}$ estimulador deve agir com ele, deve brincar cooperativamente". (RIZZO, 2006, p. 129) Quando a relação com o adulto educador é gratificante, a criança confiará nele, procurando imitálo, pois conta com o mesmo como seu porto seguro para seus momentos de dificuldades, se sentindo confiante e estimulada a continuar sua ação exploratória do mundo, o que a fará alargar seus horizontes. A construção de conhecimentos a cerca do mundo e de si mesma, irá torná-la mais independente e confiante de continuar sua ação exploratória. Caso contrário, se a relação com o adulto não for frutífera, ela se recusará a experimentar coisas novas e, pior, desenvolverá medos, descobrirá caminhos de agressão ou de fuga que a distanciarão de ser independente e da aprendizagem. Por isso, a relação do educador não deve apresentar as seguintes ações: superproteção (ação que inibe, sufoca e fragiliza o indivíduo) e rejeição (desamor, negligência e abandono).
Ações essas, aparentemente opostas, mas com efeitos semelhantes quando se trata de crianças, pois poderão levá-las a se retraírem, a se sentirem inseguras, baixa autoestima, se fechando às possibilidades de crescimento e exploração do mundo. (RIZZO, 2006)

A afetividade deve ser uma constante no dia a dia da criança, devendo acontecer desde o primeiro contato entre professor e alunos. Cabe ao professor mostrar às suas crianças que as manifestações afetivas não são um privilégio da sala de aula, mas também de outros espaços da creche (Direção, biblioteca, refeitório, sala de vídeo e recreação etc.).

Conforme Oliveira et al. (2011), o professor de creche estabelece várias relações e interações tanto com as crianças, quanto com as famílias e com os demais profissionais da instituição.O seu papel na creche junto às crianças vai depender de como ele se percebe no trabalho desenvolvido, como alguém que apenas "cuida" e "toma conta" ou como alguém que contribui efetivamente para que a criança se desenvolva. Lembrando que, essas formas de pensar o seu papel são dinâmicas e podem ser modificadas com a experiência, através de programas de formação em serviço, como também, aos poucos ele vai se construindo e se transformando à medida que as crianças de seu grupo desenvolvem, propondo-lhe novos desafios.

\section{Considerações finais}

Ao longo da pesquisa percebeu-se que a instituição creche no Brasil foi uma conquista da nossa Constituição de 1988, que a definiu como um direito da criança, um dever do Estado e uma opção da família, como também das demais legislações. Enquanto instituição educativa, através do trabalho do professor e demais funcionários da creche junto à criança, esta tem a função de complementar o papel educativo das famílias. Portanto, o papel da afetividade na prática pedagógica se faz de suma importância e o professor é o grande parceiro da criança nessas situações de afetividade: observando-a, incentivando-a, perguntando-lhe, escutando-a, explicando-lhe, pegando-a no colo ou rindo com ela. Pois é ele que participa da grande aventura de construção de seus conhecimentos.

\section{Referências}

ARIÈS, P. A História Social da Criança e da Família. Rio de Janeiro: Ed. Zahar, 1981.

BRASIL. Constituição da República Federativa do Brasil(1988). Disponível em: http://www.planalto.gov.br/ccivil 03/constituicao/ constitui\%C3\%A7ao.htm. Acesso em: 10 SET 2016.

Estatuto da Criança e do Adolescente. Lei $\mathrm{n}^{\circ}$ 8.069, de 13 de junho de 1990. Disponível em: http://www.planalto.gov.br.htm. Acesso em: 12 SET 2016.

Lei de Diretrizes e Bases da Educação Nacional (LDB). Lei Federal n. ${ }^{\circ}$ 9.394, de 26/12/1996. Disponível em: http://www.planalto.gov. 
br/ccivil_03/Leis/L9394.htm. Acesso em: 10 SET2016.

. Ministério da Educação. Secretaria de Educação Básica. Referencial Curricular Nacional para a Educação Infantil. - Brasília: MEC/SEB, 1998. v. 1.

. Ministério da Educação. Secretaria de Educação Básica. Diretrizes Curriculares Nacionais para a Educação Infantil /Secretaria de Educação Básica. - Brasília: MEC, SEB, 2010.

. Ministério da Educação / Secretaria de Articulação com os Sistemas de Ensino. Plano Nacional de Educação. (MEC/ SASE), 2014. Disponível em: http://pne.mec.gov.br/images/pdf/pne_conhecendo_20_metas.pdf. Acesso em: 04 OUT 2016.

. Lei $n^{0}$ 11. 274/2007. Disponível em :http://www.planalto.gov.br/ ccivil_03/_ato2004-2006/2006/lei/111274.htm. Acesso em: 26 OUT 2016.

BUJES, Maria Isabel Edelweiss. Escola infantil: Pra que te Quero?.In: CRAIDY, Carmem, Kaercher, Gládis E. Educação Infantil: Para que te quero? Porto Alegre: Artmed, 2001.

CUNHA, Antônio Eugênio. Afetividade na prática pedagógica: educação, TV e escola. Rio de Janeiro: Wak Editora, 2008.

EICHMANN, Lara Miriam Lopes .As Rotinas na Creche: a sua importância no desenvolvimento integral da criança dos 0 aos 3 anos.2014. Disponível em: https://comum.rcaap.pt/bitstream/10400.26/6597/1/ Vers $\%$ C3\%A30\%20Final_AS_ROTINAS_NA_CRECHE_-_A_SUA_ IMPORT $\%$ C3\%82NCIA NO DESENVOLVIMENTO INTEGRAL DA_CRIAN\%C3\%87A_DOS_0_AOS_3_ANOS.pdf. Acesso em 12 AGO $201 \overline{5}$.

FARIA, Sonimar Carvalho. História e Políticas de Educação Infantil.In: azolo et al (orgs). Educação infantil em Curso. Rio de Janeiro: Ravil, 1997.

KRAMER, Sonia. A política do pré-escolar no Brasil: a arte do disfarce. São Paulo: Cortez, 2006.

MORGADO, R. Famílias(s):permanências e mudanças. Os lugares sociais de mulheres e homens. A questão Social do Novo Milênio. VIII Congresso Luso-Brasileiro de Ciências Sociais. Coimbra, setembro de 2004.

OLIVEIRA, Zilma de M. R. Educação Infantil: fundamentos e métodos. 6 ed. São Paulo: Cortez, 2010.

OLIVEIRA, Zilma de M. R. et al. Creches: crianças, faz de conta \& cia. 16. ed. Petrópolis, RJ: Vozes, 2011.

PANIAGUA, Gema; PALACIOS, Jesús. Educação Infantil: resposta educativa à diversidade. Porto Alegre: Artmed, 2007.

RIZZO, Gilda. Creche: organização, currículo, montagem e funcionamento. 4. ed. Rio de Janeiro: Bertrand Brasil, 2006.

SANCHES, E. C. Creche: realidade e ambigüidades. Petrópolis, RJ, Vozes, 2003.

WALLON, H. A evolução psicológica da criança. Lisboa: Edições 70, 1995. 